\title{
Treatment of Neovascular Age Related Macular Degeneration
}

\author{
Ratimir Lazić and Nikica Gabrić \\ University Eye Clinic Svjetlost Zagreb \\ Croatia
}

\section{Introduction}

Neovascular Age Related Macular Degeneration (nAMD) has been a therapeutic challenge until recently. The natural course of the disease leads to a great deterioration of visual acuity and is considered to be the leading cause of legal blindness in people 50 years of age or older, especially in the Western countries.

Until the end of the last century, no intervention could alter the natural history of the disease. Only in the last few decades, the retina specialists began to intervene in order to minimize the visual loss in those patients. Last ten years have been especially exciting as the new treatment modalities emerged and for the first time we could not only halt the progression of the deterioration, but rather improve vision in some patients.

In this chapter we will present therapeutic modalities which were applied chronologically and then we will present the up to date treatment options. Finally we will briefly summarize new emerging drugs which are still under clinical evaluation.

\section{Past treatments}

\subsection{Laser photocoagulation}

The first major clinical trial evaluating laser photocoagulation in treatment of nAMD was performed in the 1980-ies, at times when no treatment modality could change natural course of this disease. However, the Macular Photocoagulation Study (MPS) (1), which took 5 years to complete, demonstrated that argon laser photocoagulation could postpone or even prevent significant visual loss in patients with juxtafoveol and extrafoveol choroidal neovascular membranes (CNV).

It was later shown that some benefits of reducing the damage generated by the natural course of the disease could be achieved by performing laser treatment on subfoveol CNV as well (2). As the reduction of visual acuity occurred immediately after the laser treatment, patients' dissatisfaction became a major issue.

\subsection{Photodynamic therapy}

Photodynamic therapy (PDT) represented the first specific treatment option in treating nAMD and the treatment protocol consisted of intravenous application of a photosensitive 
drug verteporfin, which was then activated by a 693-nanometer-long, verteporfin-sensitive laser beam light.

Verterporfin activation was followed by a series of photochemical reactions, resulting in destruction and thrombosis of endothelial cells in the neovascular membrane complex (3). The PDT had a double selectivity mechanism:

1. Verteporfin was utilized only by cells with accelerated metabolism (neovascular membrane),

2. Laser beam was applied only to the area of $\mathrm{CNV}$.

With verteporfin accumulating itself selectively within the neovascular complex, the collateral damage to surrounding healthy tissue was minimal. Verteporfin was in circulation carried by plasma lipoproteins, which were utilized by endothelial cells due to accelerated metabolism of neovascular complex. Within the area illuminated by the laser beam, shortacting free oxygen radicals induced endothelial cell damage, which process occurred through lipo and cyclooxigenase modulated pathways, the final result being trombocyte aggregation and vasoconstriction of neovascular complex vessels (4). The slow metabolism of normal blood vessels made the utilization of verteporfin-carrying lipoproteins in normal vessels slow as well. Verterporfin was utilized by neovascular complex vessels within 15 minutes. It took 30 minutes for normal blood vessels to utilize verteporfin. Therefore, the laser beam of 90 seconds duration must had been applied to the neovascular membrane no later than 30 minutes after the infusion was started, in order to prevent damage to normal blood vessels. The exact size and location of neovascular complex was determined by fluorescein angiography, which was a precondition to laser application.

Treatment of AMD with Photodynamic Therapy (TAP) study (5) was a double blind placebo controlled randomized clinical trial evaluating the efficacy of PDT in treatment of minimally classic CNV. 609 patients were enrolled (402 in the verteporfin group and 207 in the placebo group). The treatment was repeated every 3 months in case of relapse of leakage or continuous leakage, which was confirmed by fluorescein angiography. At 12 month followup $61.2 \%$ of patients from the verteporfin group, compared to $46.4 \%$ patients from the placebo group lost less than 3 logMar lines (minimal angle resolution logarithm) or 15 letters which was statistically significant. At 24 months follow-up, 213 (53\%) patients from the verteporfin group, compared to 78 (38\%) patients from the placebo group lost fewer than 3 lines (6). The mean visual acuity was 1.3 lines better in the verteporfin group. The eyes treated with verteporfin had a $16 \%$ better chance for visual improvement by 1 or more lines, compared to the placebo group. The benefits of the verteporfin treatment were higher in case of the predominantly CNV (at least $50 \%$ of the neovascular complex has a classic component): $33 \%$ of patients from the verteporfin group lost 3 or more lines, compared to $61 \%$ of patients from the placebo group after 12 months. If CNV was completely classic, the results were even better: $23 \%$ of patients from the verteporfin group lost fewer than 3 lines, whereas in the placebo group, $73 \%$ of patients lost 3 or more lines.

In case of the minimally classic type of the $\mathrm{CNV}$, results were however modest - positive effects of the treatment were noticed only if the maximal diameter of neovascular lesion was smaller than 4 disc diameters. The efficacy of the PDT for the minimally classic CNV with the greatest diameter of lesion up to 6 discs was later confirmed by the VIM study (Verteporfin Therapy of Subfoveal Minimally Classic CNV in AMD) (7). 
The VIP study (Verteporfin in Photodynamic Therapy) evaluated PDT in patients with occult $\mathrm{CNV}$ and showed that 121 (54\%) patients from the verteporfin group lost fewer than 15 letters during 24 months of the follow-up, compared to $76(67 \%)$ patients from the control group (8), whereby the best results were displayed by the patients with lesions smaller than 4 disc diameters or with the initial visual acuity better than 20/50 (9).

The mentioned studies demonstrated the efficacy of the PDT with verteporfin in maintaining the visual acuity or slowing down visual loss. It was the very first time that we could positively interfere with the natural course of the disease using PDT.

\subsection{Surgical treatment}

Surgical techniques in treatment of nAMD included submacular surgery, macular translocation, and submacular hemorrhage displacement.

Macular translocation was a surgical procedure involving the detachment of the retina along with macula in order to move or translocate fovea from the diseased RPE onto healthy RPE. Although there had been reports of case series with quite good visual outcomes after the surgery, severe complications could arise during the process of retinal displacement $(10,11)$. Therefore nowadays macular translocation may not be considered for most patients with nAMD given the treatment options already available. In the anti-VEGF era macular translocation may be employed in patients either with very advanced AMD or in those patients with disease recalcitrant to anti-VEGF therapy.

Unfortunately the surgery undertaken in a very advanced cases wouldn't result in significant improvement of vision as the degenerative process had already damaged the retinal macular tissue along with the diseased underlying RPE: but retina specialist are reluctant to recommend macular translocation at the stage of the disease while macular retina is still viable at which point macular translocation would result in better functional outcome.

The full macular translocation surgery involved a detachment of the entire retina from the RPE by subretinal infusion of balanced saline solution fluid via 40 gauge needle with 360 degrees circumferential retinotomy followed by the retinal rotation under perflorocarbon liquid during which process macula was displaced onto healthy RPE. The site of the 360 retinotomy and the holes artificially created for detaching retina were sealed by endolaser photocoagulation. Then an exchange between perflorocarbon liquid with silicone oil was performed. After 3 months silicone oil was removed.

\section{Current treatment options}

\subsection{Anti-VEGF drugs}

\subsubsection{Pegaptanib sodium}

An additional step forward was made by introducing the anti-VEGF drugs as a treatment option for nAMD. Pegaptanib sodium (Macugen) was actually a synthetically derived polyonucleotide ligand binding specifically to VEGF-A 165 isoform. The affinity to only one isoform of VEGF cluster explained pegaptanib sodium inferior therapeutic effect, compared to non-selective infibitors of all VEGF isoforms. 
Data from VISION trial indicated that $70 \%$ of the treated patients with intravitreal pegaptanib sodium given on a 6-week basis lost fewer than 15 letters during a 24 month follow-up, compared to $55 \%$ of patients from the placebo group. The mean visual acuity decreased by 8 letters during the follow-up period in the patients treated with intravitreal pegaptanib sodium in this study (12).

\subsubsection{Ranibizumab}

Ranibizumab is a humanized antigen-binding FAB fragment monoclonal antibody towards human VEGF-A, derived from rodents. It is produced by recombinant technology from Escherichiae coli, with molecular weight of 48 kilodaltons. Ranibizumab inhibits all VEGF-A isoforms. Furthermore, it penetrates well through all layers of retina up to choroidea. The binding affinity of ranibizumab is 5-20 times higher comparing to bevacizumab(13). Ranibizumab was approved for intravitreal application in 2006.

A large multicentric randomized clinical trial MARINA (Ranibizumab in Treatment of Occult and Minimally Classic CNV)(14) and ANCHOR (Ranibizumab in Treatment of Predominantly Classic CNV)(15) confirmed that ranibizumab, given on a monthly basis substantially improved visual acuity compared to placebo. The MARINA study enrolled 716 patients and evaluated the efficacy of monthly ranibizumab $(0.3 \mathrm{mg}$ and $0.5 \mathrm{mg})$, versus placebo given for 24 months. In the ranibizumab groups over $90 \%$ of patients lost fewer than 15 letters (or 3 lines) compared to $62 \%$ patients from the placebo group. One third of patients from the ranibizumab group $(0.5 \mathrm{mg})$ gained 15 letters or more, while in the placebo group only $5 \%$ of patients achieved this effect. This was a significant breakthrough compared to all previous treatment options. Mean visual acuity improved by 7.2 letters (about 1 line of logMAR) at 12 month follow-up in the ranibizumab group (0.5mg), while in the placebo group, the visual acuity deteriorated by more than 10 letters. The benefit in visual acuity was maintained at 24 months. During 24 months, presumed endophthalmitis was identified in five patients $(1.0 \%)$ and serious uveitis in six patients $(1.3 \%)$.

The ANCHOR study enrolled 423 patients and compared the efficacy and safety of ranibizumab given on a monthly basis with standard PDT with verteporfin. The follow-up period was 24 months. At the end of the study, over $90 \%$ of patients from the ranibizumab group and $65 \%$ of patients from the photodynamic group lost fewer than 15 letters. Furthermore, over one third of patients from the ranibizumab group gained 15 letters or more, compared to $5.6 \%$ of patients from the PDT group. Mean visual acuity improved by 11.3 letters in the ranibizumab group $(0.5 \mathrm{mg})$, whereas patients from the photodynamic group had mean decrease of 9.5 letters. Reduction in central retinal thickness, measured by OCT, was also observed through the follow-up.

Endophthalmitis or serious uveitis occurred in around $2 \%$ of patients from the ranibizumab group $(0.5 \mathrm{mg})$. Even though visual results were good, it took 24 injections over 2 year period to achieve it. Several studies were conducted in order to see whether a number of retreatments could be reduced with sustained visual results.

PIER study (16) analyzed a treatment protocol of three consecutive monthly injections of ranibizumab, followed by injections every three months. The results of this study were inferior when compared to the results achieved by the MARINA and ANCHOR trials, in particular between 3rd and 12th month when injections were given quarterly. 
In PRONTO study (17) patients received 3 injections of ranibizumab on a monthly basis and thereafter as needed, based on strictly defined criteria, which included visual acuity decline, reoccurrence of fluid and central retinal thickness increase measured by OCT and clinical manifestation of macular hemorrhage. The results obtained by the PRONTO study were comparable to those of the MARINA and ANCHOR studies, but the number of injections required was lower: 5 injection of ranibizumab in the PRONTO versus 12 injections in the MARINA and the ANCHOR per year.

SAILOR study (18) was designed with the purpose of confirming the results obtained by the PRONTO study. The SAILOR study lasted for 12 months. After three monthly injections of ranibizumab the additional injections were given based on predefined criteria, similar to those applied in the PRONTO study. The results of the SAILOR study were better than the ones of the PIER study, but not as good as those of the MARINA and ANCHOR, where injections were given on a monthly basis. The rate of the systemic side effects indicated a satisfactory safety profile.

SUSTAIN study (19) confirmed the results given by the SAILOR study. The SUSTAIN study achieved better results than the PIER study, but inferior to those of the MARINA and ANCHOR and the PRONTO studies. During a 1-year follow-up period, mean number of injections applied was around 5 and visual acuity improved by 3.6 letters. Central retinal thickness was reduced by 92 microns.

The HORIZON study (20) was a sequel to the MARINA and ANCHOR studies, its main purpose was to analyze the long term follow-up results and furthermore, to switch from monthly dosing to dosing as needed and to observe an impact on visual acuity. Additional treatment was required in more than $60 \%$ of patients during the 2 year follow-up period. Visual gain achieved after two years of monthly injections of ranibizumab was not maintained with less frequent dosing of ranibizumab.

The monthly dosing remained, however, the best way to preserve the visual acuity. Any reduction in number of injections led to inferior visual outcome. Due to frequent dosing and other paramedical factors, regular monthly drug application presented a great burden to substantial number of patients.

\subsubsection{Bevacizumab}

Bevacizumab (Avastin) is a humanized recombinant monoclonal mouse antibody. A molecular weight of bevacizumab is 149 kilodaltons. It is active against all VEGF-A isoforms. Bevacizumab has been approved as an intravenous drug in the treatment of metastatic colon cancer (21), along with chemotherapy. It helps to induce the reduction of the tumor volume by deprivation of tumor vascularization (22).

In 2005, bevacizumab was administered as ocular treatment for the first time. First bevacizumab trial included 9 patients with nAMD. Bevacizumab was given intravenously $(5 \mathrm{mg} / \mathrm{kg})$ at two week intervals resulting in 12-letters gain with a significant reduction of intraretinal macular edema at the 12 week follow-up period (23). 7 patients experienced mild hypertension as a side-effect.

Due to systemic side-effects (hypertension, gastrointestinal bleeding, thromboembolic events), bevacizumab was then applied intravitrealy in a concentration of $1 \mathrm{mg} / 0.1 \mathrm{ml}$, which was a significantly lower dose compared to the systemic one, while the good visual 
outcome was maintained (24). Despite its large molecular weight, bevacizumab showed satisfying penetration into subretinal space, without any harmful neurophysiologic effects (25). Many clinical trials confirmed later the efficacy of bevacizumab in improving the visual acuity, reducing the retinal exudation and the acceptable safety profile $(26,27,28,29,30)$.

Bevacizumab and ranibizumab exhibit differences and similarities in the treatment of nAMD:

- Both drugs inhibit all VEGF-A isoforms.

- Bevacizumab has weaker affinity towards the VEGF factor than ranibizumab.

- Bevacizumab has larger molecular weight, which could interfere with the penetration ability.

- Given that the bevacizumab is a full antibody with the Fc fragment, whereas ranibizumab is only an antibody fragment, it might be more immunogenic.

Several studies showed no difference in efficiency between ranibizumab and bevacizumab(31,32,33). Interesting results came from a study which concluded that functional result were alike, however bevacizumab needed a longer period of time to achieve resolution of retinal edema than ranibizumab: 60 versus 90 days. The period of the drug potency was 110 days for bevacizumab, and 70 days for ranibizumab, suggesting a longer interval of bevacizumab dosing(34).

Comparison of AMD Treatment Trials (CATT) study (35) was designed to compare ranibizumab and bevacizumab in treatment of nAMD. 1208 patients were enrolled. Patients were randomized into four study arms: ranibizumab monthly or as needed and bevacizumab monthly or as needed. Ranibizumab and bevacizumab showed equivalent results in terms of efficiency. Patients treated with monthly bevacizumab gained 8 letters, while patients treated with monthly ranibizumab gained 8.5 letters after 12 month follow-up period. In as-needed arms bevacizumab was equivalent to ranibizumab with 5.9 and 6.8 letters gained.

Ranibizumab as needed was equivalent to monthly ranibizumab, while comparison between bevacizumab as needed and bevacizumab monthly showed inconclusive results. Rates of death, myocardial infarction, and stroke were similar for patients receiving either ranibizumab or bevacizumab. The proportion of patients with serious systemic adverse events (SSAE) requiring hospitalization was higher with bevacizumab than with ranibizumab arms (24.1\% vs. $19.0 \%)$. The importance of the CATT trial was in reporting the same efficacy of bevacizumab in a major randomized clinical trial. The raised concern with higher incidence of SSAE in bevacizumab is worth of noting but still inconclusive and needs to be further analyzed.

\section{Drugs under investigation}

\subsection{VEGF Trap Eye (aflibercept)}

To initiate molecular mechanism of neovascularization, it is essential for the VEGF to bind to endothelial cell receptors VEGFR1 and VEGFR2, which act as transmembrane tyrosine kinases.

By binding VEGF to their outer subunit, tyrosine kinase is activated which then triggers intracellular signaling pathways. The VEGF Trap Eye is a fusion protein containing VEGFR1 
and VEGFR2 similar domains combined with Fc immunoglobulin segment (36). This means that VEGF Trap Eye has antibody inhibiting characteristics for all VEGF-A isoforms and binding affinity 800 times greater than bevacizumab. A clinical trial with 25 patients has shown good tolerability and increased visual acuity 6 weeks after single intravitreal injection (37).

VIEW 1 and VIEW 2 were phase III, randomized, double- masked, clinical trials $(38,39)$ evaluating VEGF Trap Eye effect on maintaining and improving vision as compared to ranibizumab.The studies have been completed in 2011. VIEW 1 was conducted in USA and VIEW 2 was conducted in Asia, Europe, Japan and Latin America. In both studies patients were randomized evenly to one of four treatment groups:0.5 $\mathrm{mg}$ ranibizumab monthly, VEGF trap $0.5 \mathrm{mg}$ monthly, VEGF trap $2 \mathrm{mg}$ monthly or VEGF trap $2 \mathrm{mg}$ dosed every 8 weeks following a tree-injection loading dose.

VIEW 1 enrolled 1217 patients. Prevention of moderate vision loss was achieved in 94-96\% of patients from all four groups showing VEGF Trap Eye non inferior to ranibizumab. Mean gain in visual acuity in all four groups was as follow: VEGF Trap $0.5 \mathrm{mg}$ group achieved a mean gain of seven letter, the 2 mg VEGF Trap montly group a mean gain of 11 letters, the 2 mg VEGF Trap dosed every two months after initial loading dose gained a mean of 8 letters while ranibizumab monthly group gained a mean of 8 letters. The only statistically significant difference in visual gain was between patients receiving VEGF Trap Eye $2 \mathrm{mg}$ monthly compared to ranibizumab monthly with $\mathrm{p}<0.01$ (11 letter vs. 8 letter gain at week 52) showing superiority of VEGF Trap Eye dosed $2 \mathrm{mg}$ monthly.

International VIEW 2 study enrolled 1240. As in VIEW 1 study, prevention of moderate vision loss was achieved in 94- 96 percent of patients from all four groups confirming non inferiority of VEGF Trap Eye at all doses compared to monthly ranibizumab.

A generally favorable safety profile was observed for both VEGF Trap Eye and ranibizumab. The most frequent ocular adverse events were conjunctival hemorrhage, macular degeneration, eye pain, retinal hemorrhage, and vitreous floaters.

In conclusion both VIEW 1 and VIEW 2 studies showed VEGF-Trap-Eye being non inferior to monthly ranibizumab in prevention of moderate vision loss with good safety profile and potential for VEGF-Trap to achieve equally superior visual results as monthly ranibizumab with less frequent dosing. When dosed 2 mg monthly VEGF Trap Eye even showed superior in terms of vision gain compared to ranibizumab monthly

\subsection{Interfering RNA}

Small interfering RNAs (siRNA) are synthetic nucleotide chains, containing 20 nucleotides.

While VEGF antibodies neutralize the already produced VEGF, siRNA interferes with VEGF -A messenger RNA (mRNA)(40,41), inhibiting thereby the production of all VEGF-A isoforms.

As a result, the already produced VEGF persists within the eye for a couple of the first treatment weeks, leading to delayed therapeutic effect.

SiRNA 027 interferes with the VEGF-R1 mRNA production. As demonstrated by CNV models, intravitreal and periocular injection of siRNA resulted in a significant CNV lesion reduction (42). 
Other siRNA target hypoxia-induced transcription factor (HIF-1). This factor is important not only in tumor angiogenesis but also in normal vessel formation. HIF-1 is composed of the constitutively expressed HIF-1 beta subunit and the 3-alfa subunit. In non-hypoxia conditions, HIF-1 alpha dissolves rapidly, whereas in the hypoxic environment, HIF-1 alpha becomes stable and acts as a hypoxia-provoked inducible gene regulator (43). Currently there are no ongoing clinical trials investigating this compound in treatment of nAMD but data from previous studies showed the compound to have a potential for VEGF inhibition.

\subsection{Tyrosine kinase inhibitors}

One of the most important biochemical mechanisms of intracellular signaling mediation is reverse phosphorilation. This reaction is catalysed by kinase proteins, which transfer gphosphate ATP group to hydroxyl group of targeted proteins (44). There are 518 of such proteins in human genome, 90 of which are selective hydroxyl group tyrosine phosphorilation catalysts(45).

Cytosol tyrosine kinases are intracellular, while the receptor tyrosine kinase (RTK) have intracellular and extracellular domain and function as membrane receptors. The RTKs modulate cellular responses as such to signalling from the environment and act as various cell processes boosters of cellular proliferation, migration and survival. Otherwise the RTK signal mechanisms are well regulated, while their excessive activation can stimulate growth, survival and tumor cell metastasis development (46). Members of the VEGF and PDGF receptor group, which belong to the RTK family, promote tumor progression through various mechanisms: angiogenesis, limphangenesis and vascular permeability.

PTK 787 is a RTK inhibitor with binding affinity to VEGF receptor tyrosine kinase and thus inhibits all VEGF-A isoforms. PTK 787 displayed functional improvement of ischemic retinopathy induced in mice. A single intravitreal injection of PTK reduced angiproliferative changes compared to the control eye of each animal $(n=37)$ when retinopathy scores were compared (47). Currently there are no clinical trials of PTK 787 in treatment of nAMD, but the compound has a potential for VEGF inhibition.

\subsection{Cytokine PEDF}

Pigment Epithelial Derived Factor (PEDF), produced by retinal pigment epithelial cells is one of the most important endogenous angiogenesis inhibitors (48). The exact location of the PEDF production is on the apical side of pigment epithelial cells and contrary to VEGF it is inhibited by hypoxia.

A high PEDF concentration can be found in extracellular photoreceptor matter, vitreous and cornea, indicating its major role in maintaining the tissues avascularity (49). The PEDF's anti-angiogenic capacity has been proven in laser-stimulated CNV animal model (50). The PEDF concentrations are lower in the eyes suffering from CNVs, which is consistent with its anti-angiogenic properties. Therefore gene transferring adenovirus coding over-expression of PEDF could suppress the angiogenesis process.

\subsection{Epimacular brachytherapy}

Previously used, radiation therapy from external radiation source produced inconsistent results with high rate of side-effects. It was therefore abandoned from everyday clinical practice. Localized radiation treatment, on contrary has an ability to prevent proliferation of 
vascular tissue by inhibiting neovascularization $(51,52)$. After low-dose radiation, vascular endothelium demonstrates morphologic and DNA changes, inhibition of replication, increased cell permeability, and apoptosis. Fibroblast proliferation and subsequent scar formation, a hallmark of end-stage nAMD are also inhibited.

CNVs which contain proliferating endothelial cells due to the hypoxic environment and the produced chemokines are more sensitive to radiation treatment than the retinal vasculature and non-proliferating capillary endothelial cells and larger vessels. Therefore to reduce complication rate and to improve visual outcome epimacular brachytherapy was introduced. It uses strontium-90 beta radiation as radiation source (NeoVista, Fremont, CA.). Total radiation dose is 24 gy. Epimacular brachytherapy is designed to deliver precisely controlled dose of beta radiation to $\mathrm{CNV}$ lesion. Compared to previously used radiation therapy strontium- 90 beta radiation is ideal for treating retina because its delivery system ensues no collateral damage to surrounding retinal tissues $(53,54)$. After pars plana vitrectomy is done, radiation applicator is placed directly above $\mathrm{CNV}$ lesion and held for 2-4 minutes. This has a dual effect: vitrectomy increases retinal oxygen saturation and in contrast to external beam radiotherapy a larger dose of radiation can be delivered to the macula with less irradiation of normal ocular structures and surrounding tissues. This novel device is currently being evaluated in two prospective, randomized, controlled trials in treatment-naive subjects: the CNV Secondary AMD Treated with Beta Radiation Epretinal Therapy (CABERNET) and in subjects already treated with anti-vascular endothelial growth factor therapy: Macular Epiretinal Brachytherapy versus Lucentis Only Treatment (MERLOT).

\subsection{Combination treatment}

Having in mind the multiplicity of signaling mechanisms which are crucial for the development of nAMD as well as multistage evolution of the disease, combination treatments could have synergistic effect in halting the progression of disease.

The anti-VEGF and PDT with verterpofin have up to now been the only available options mostly used in everyday clinical practice. The introduction of the PDT in treatment of nAMD in 2001 for the very first time affected natural course of the disease. This was achieved by acting on the last arm in pathophysiologic cascade of neovascularisation process: destruction of already formed neovascular membrane.

The second major breakthrough in the therapy of nAMD was the introduction of anti-VEGF drugs.

The anti-VEGF drugs act one step earlier in pathogenesis of the disease opposite to PDT, by preventing neovascularization and inducing regression of the newly formed neovascular blood vessels still dependent on VEGF support. Unlike PDT, which could only slow down the disease progression and reduce the visual acuity decline, patients treated with antiVEGF could expect their visual acuity to be maintained and even improved in significant number of patients.

Although the anti-VEGF drugs are for the time being the best treatment option in managing nAMD, there are a few setbacks that caused the initial enthusiasm to drop. Regardless of anti-VEGF frequent dosing, a significant number of patients suffer further visual acuity deterioration throughout the course of the disease. Frequent intravitreal applications raise a risk for local complications such as: endophthalmitis, uveitis, vitreous hemorrhage, retinal detachment, posterior vitreous detachment etc. Despite continuous anti-VEGF blockage, 
active signaling pathways and expression of VEGF genes lead to continuous VEGF production, so continuous and regular treatment over a longer period of time is required as anti-VEGF drugs block only already produced VEGF.

Besides already mentioned increased complication risks, another problem is cost of antiVEGF drugs as well as discomfort caused by intravitreal mode of application which ultimately leads to poor patient compliance. Having this in mind, new treatment options should be investigated. A potential new therapy regimen should actually have the following characteristics:

1. Increased treatment efficacy.

2. Prolonged remission period.

3. Low reapplication rate.

4. Low complications rate.

5. Acceptable cost.

6. Comfortable mode of administration.

In pursuit of better treatment modality in 2006 we proposed a combination of PDT and antiVEGF with an idea to address two different steps of CNV formation: VEGF induced neovascularization and destruction of already formed CNV. In future a third potential drug acting on gene transcription could also be included thus preventing revascularization even earlier in the cascade of events. Further experimental and clinical trials are needed to support this hypothesis.

Clinical studies conducted between 2001 and 2006, i.e. before the introduction of anti-VEGF drugs, investigated a possibility of a combination treatment for nAMD using PDT and trimacinolone. Trimacinolone is a long-acting corticosteroid, otherwise employed in treatment of rheumatic diseases of locomotor system. In ophthalmology trimacinolone was used intravitreally for diabetic macular edema. A significant number of studies demonstrated the same functional outcome of triamcinolone and PDT combined versus the PDT alone, with longer remission interval and a reduced need for additional reapplications of PDT when combined with triamcinolone $(55,56,57,58)$. Since the combination therapy of triamcinolone and PDT proved to have synergistic effect, we hypothesized that combination of anti-VEGF drugs and PDT could either improve functional outcome or extend treatment intervals in patients with nAMD. We suggested a possible synergistic effect due to different target-points of choroidal neovascularization process: PDT inducing vascular occlusion to already formed neovascular vessels while anti-VEGF drugs preventing formation of new neovascular tissue, inducing regression of the newly formed VEGF-dependent vessels and reducing permeability of neovascular tissue. Additional production of VEGF after PDTinduced hypoxia of choriocapilaris and inflammatory reaction due to neovascular tissue destruction could also be targeted with anti-VEGF drugs. In 2006, we concluded a pilot study on a small number of patients, divided into three groups - one treated with PDT, one with bevacizumab and the last one with bevacizumab and PDT together. The achieved results indicated possible synergistic effect: the visual acuity was better in patients who underwent combination therapy than in monotherapy groups, whereas the remission period was longer in combination group (59).

Other studies also indicated possible amplifying effect of the combination treatment with PDT and anti-VEGF. Also some studies included addition of intravitreal corticosteroid to address the inflammatory component of the disease (60-70). 
The RADICAL was a phase II, multicentric, randomized, single-masked study of 162 patients with nAMD. The purpose of the study was to determine whether the PDT combined with ranibizumab reduced re-treatment rate compared with ranibizumab monotherapy. Patients were randomized into 4 groups: ranibizumab monotherapy, triple therapy with quarterfluence verteporfin followed by ranibizumab and then dexamethasone, triple therapy with half-fluence verteporfin followed by ranibizumab and then dexamethasone and double therapy with half-fluence verteporfin followed by ranibizumab. The 24-month results showed significantly fewer retreatments in combination groups than in ranibizumab monotherapy group. Mean visual acuity change was not statistically different among the treatment groups. Through 24 months, patients in the triple therapy half-fluence group had a mean of 4.2 retreatment visits compared with 8.9 for patients who received ranibizumab monotherapy. At the month 24, mean VA in the triple therapy half-fluence group improved 1.8 letters fewer compared with the ranibizumab monotherapy group which was not significantly inferior. This results show a potential of combination therapy in reducing the retreatment rate while sustaining the same visual outcome. The concept of combination therapy with new emerging drugs could further show a synergistic effect when those drugs would be combined.

The displayed figures depict 2 patients from an extension of our pilot study throughout the period of 3 years. Both patients were treatment naïve. First patient N.U. was randomized to bevacizumab monotherapy treatment group and was treated with bevacizumab only and second patient R.K. was randomized to combination treatment group and was treated with combination treatment initially and then bevacizumab as needed. The second patient treated with combination treatment required less intravitreal bevacizumab injections during a 3 year follow-up period.

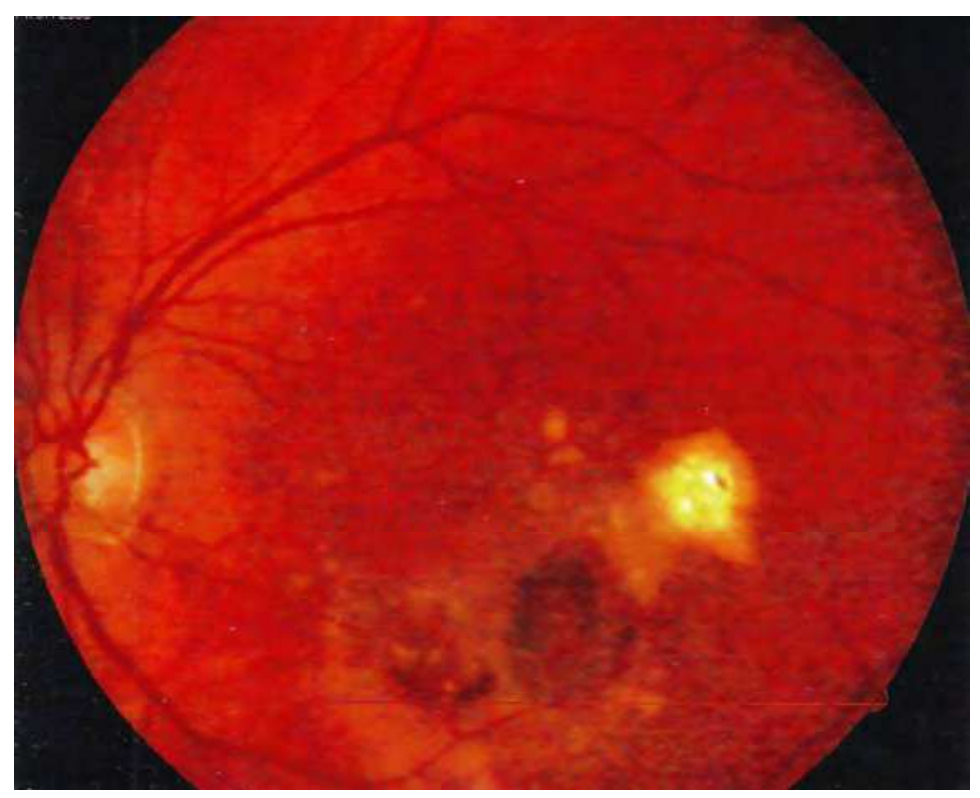

Fig. 1. Patient N.U. 76 yrs., fundus photography at baseline before bevacizumab treatment showing exudation and hemorrhage. 

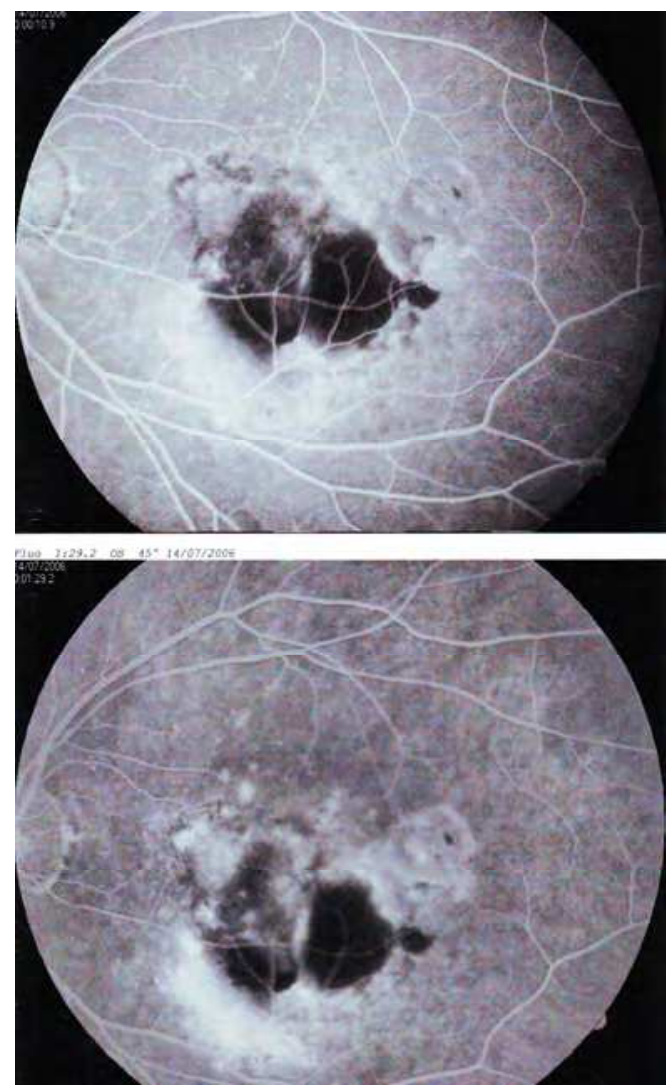

Fig. 2. Patient N.U. 76 yrs, early and late phase fluorescein angiography pictures at baseline before bevacizumab treatment showing blockage of retrofluorescence by hemorrhage, and a leakage of dye from the CNV.

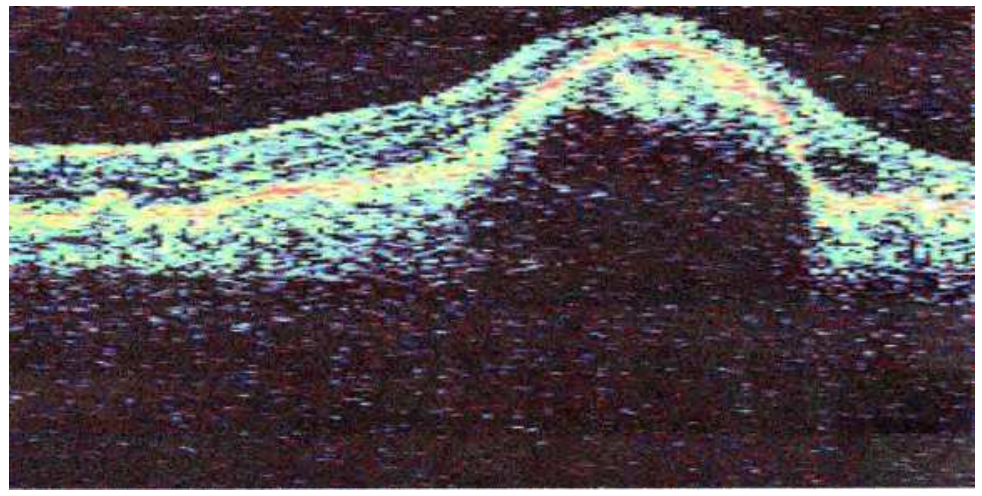

Fig. 3. Patient N.U. 76 yrs OCT scan (Zeiss Stratus II device) at baseline before bevacizumab treatment. It shows accumulation of intraretinal and subepithelial fluid. 


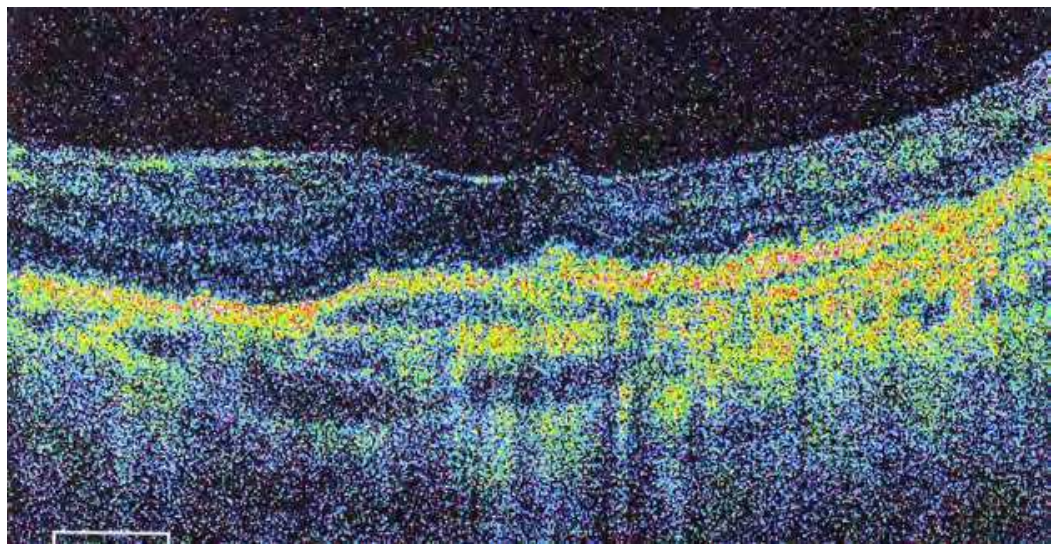

Fig. 4. Patient N.U. 76 yrs, OCT scan (Optopol SD device). It shows the resolution of fluid 3 years after repeated intravitreal bevacizumab treatment.

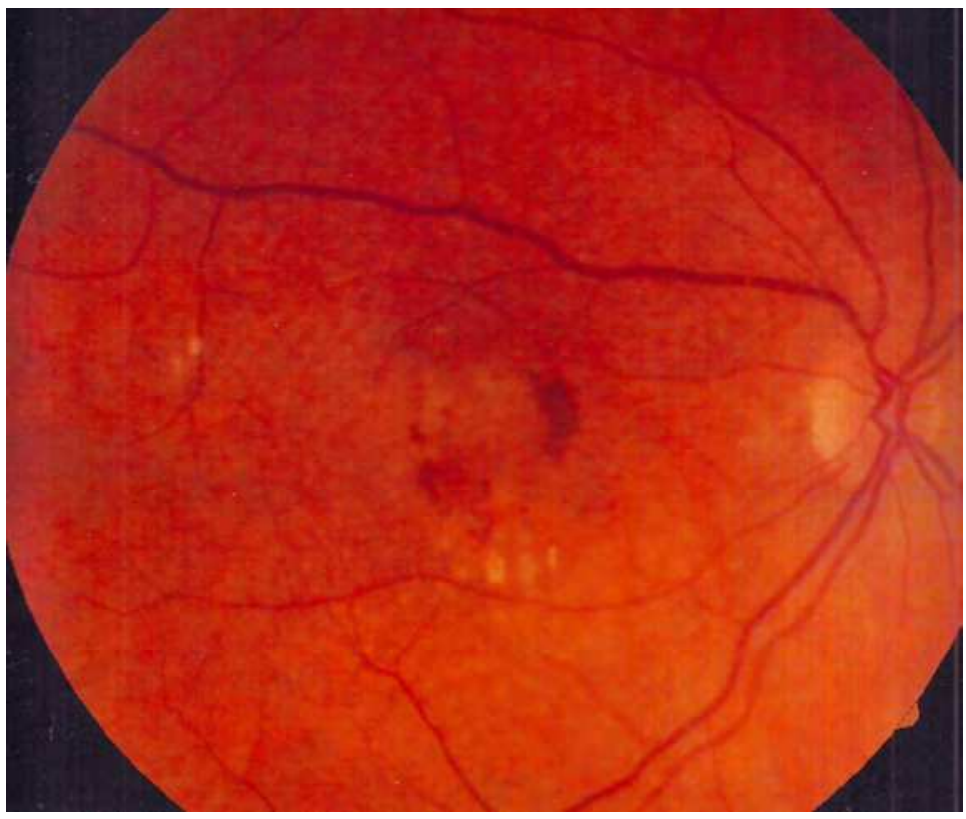

Fig. 5. Patient R.K. 74 yrs., fundus photography at baseline before combination treatment (bevacizumab + PDT) showing exudation and hemorrhage. 

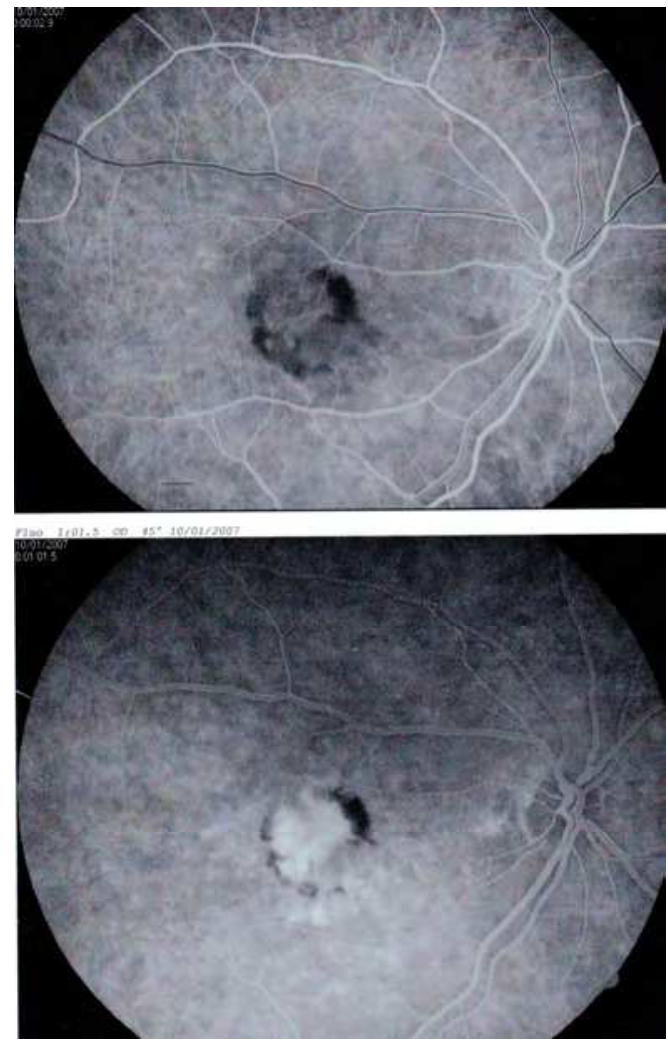

Fig. 6. Patient R.K. 74 yrs, early and late phase of fluorescein angiography at baseline before combination treatment (bevacizumab+PDT). It shows marginal hemorrhage and leakage of dye from the CNV.

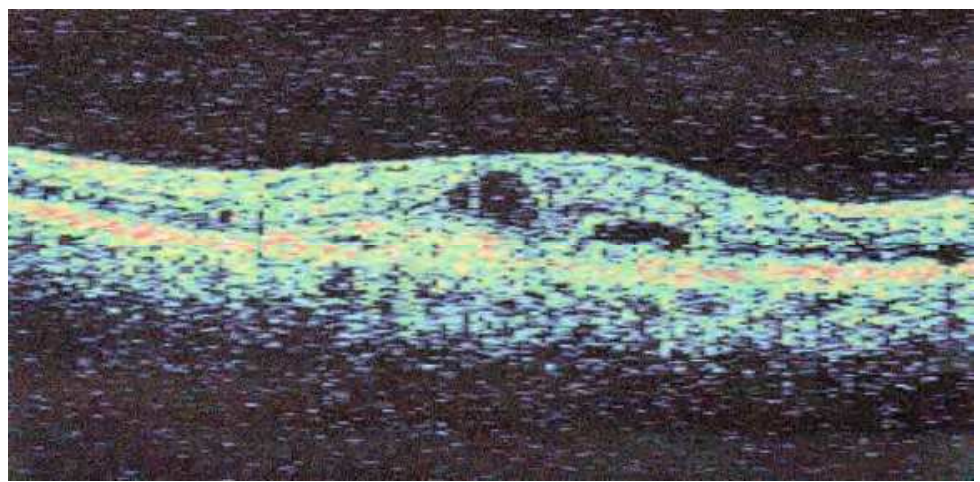

Fig. 7. Patient R.K. 74 yrs OCT scan (Zeiss Stratus II device) at baseline before combination treatment. It shows accumulation of intraretinal and subretinal fluid. 


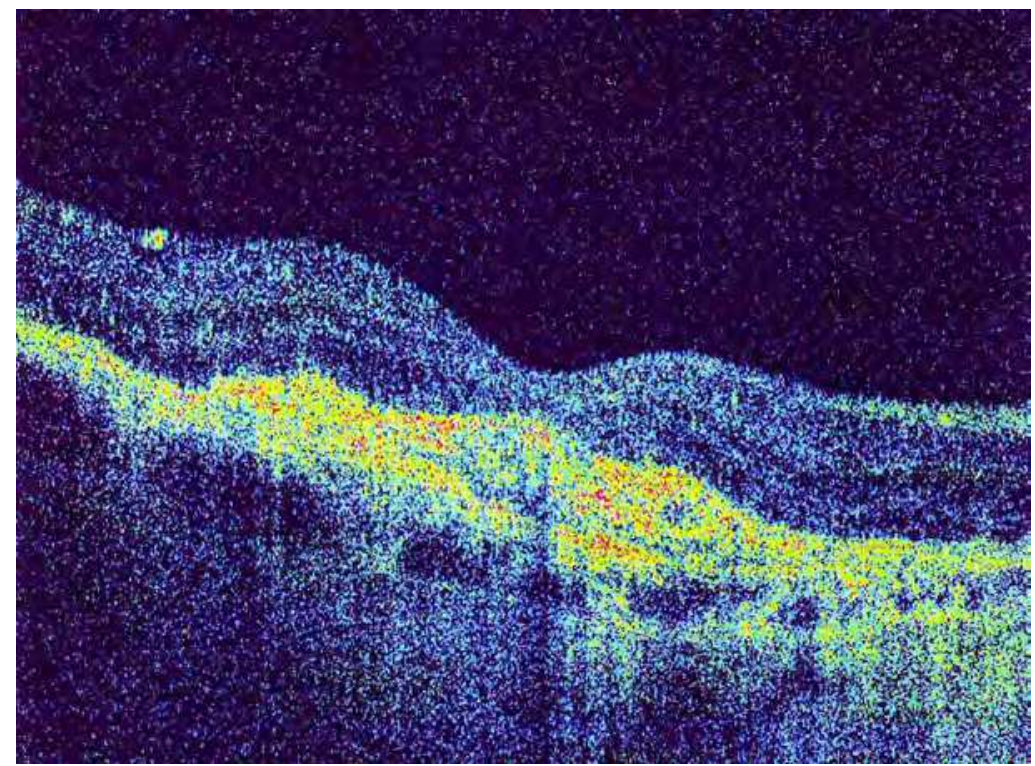

Fig. 8. Patient R.K. 74 yrs OCT scan (Optopol SD device). It shows resolution of fluid 3 years after initial combination treatment of intravitreal bevacizumab and photodynamic therapy followed by repeated bevacizumab treatment.

In summary we can conclude that new emerging therapies for nAMD for the first time in history managed to revert the natural history of disease. In significant number of patients some improvement could be achieved while in a majority of patients the treatment resulted in maintenance of visual acuity. However the significant burden of repeated intravitreal injections, increased risks of ocular and possibly systemic side effects and decreased patients' compliance lead to further visual loss over time. Also some patients do not respond to the available treatments favorably. So the need for new and more efficient drugs in terms of better functional outcome and reduced need for retreatment is fully justified. VEGF-Trap-Eye is pending approval and it may show to be more potent and requiring less treatment. Also combination of present treatment modalities should further be evaluated. Hopefully with better understanding of the genes responsible for different variants of nAMD we could either employ some form of genetic therapy or we can adjust already available treatments according to a certain genotype in order to achieve most favorable results.

\section{References}

[1] Macular Photocoagulation Study Group. Argon laser photocoagulation for neovascular maculopathy. Five-year results from randomized clinical trials. Arch Ophthalmol 1991;109(8):1109-14.

[2] Macular Photocoagulation Study Group. Subfoveal neovascular lesions in age-related macular degeneration. Guidelines for evaluation and treatment in the macular photocoagulation study. Arch Ophthalmol 1991;109(9):1242-57. 
[3] Schmidt-Erfurth U, Laqua H, Schlotzer-Schrehard U, Viestenz A, Naumann GO. Histopathological changes following photodynamic therapy in human eyes. Arch Ophthalmol 2002;120:835-44.

[4] Fingar VH, Wieman TJ, Wiehle SA, Cerrito PB.The role of microvascular damage in photodynamic therapy: the effect of treatment on vessel constriction, permeability, and leukocyte adhesion.Cancer Res 1992;52(18):4914-21.

[5] Treatment of age-related macular degeneration with photodynamic therapy (TAP) Study Group. Photodynamic therapy of subfoveal choroidal neovascularization in agerelated macular degeneration with verteporfin: one-year results of 2 randomized clinical trials--TAP report.Arch Ophthalmol 1999;117:1329-45.

[6] Treatment of Age-Related Macular Degeneration with Photodynamic Therapy Study Group. Photodynamic therapy of subfoveal choroidal neovascularization in agerelated macular degeneration with verteporfin: two-year results of 2 randomized clinical trials--TAP report 2. Arch Ophthalmol 2001;119:198-207.

[7] Azab M, Boyer DS, Bressler NM et al. Verteporfin therapy of subfoveal minimally classic choroidal neovascularization in age-related macular degeneration: 2-year results of a randomized clinical trial. Arch Ophthalmol 2005;123(4): 448-57.

[8] Bressler NM. Verteporfin therapy of subfoveal choroidal neovascularization in agerelated macular degeneration: two-year results of a randomized clinical trial including lesions with occult with no classic choroidal neovascularizationverteporfin in photodynamic therapy report 2. Am J Ophthalmol 2002;133:168-9.

[9] Barbazetto I, Burdan A, Bressler NM et al. Photodynamic therapy of subfoveal choroidal neovascularization with verteporfin: fluorescein angiographic guidelines for evaluation and treatment--TAP and VIP report No. 2. Arch Ophthalmol 2003;121:1253-68.

[10] McLeod D. Foveal translocation for exudative age related macular degeneration. Br J Ophthalmol. 2000;84:344-345.

[11] Akduman L, Karavellas MP, MacDonald JC, Olk RJ, Freeman WR.Macular translocation with retinotomy and retinal rotation for exudative age-related macular degeneration. Retina. 1999;19:418-423.

[12] Graroudas ES, Adamis AP, Cunningham ET Jr et al. Pegaptanib for neovascular agerelated macular degeneration. N Engl J Med 2004;351(27):2805-16.

[13] Ferrara N, Damico L, Shams N et al. Development of ranibizumab, an anti-vascular endothelial growth factor antigen binding fragment, as therapy for neovascular age-related macular degeneration. Retina 2006;26:859-70.

[14] Rosenfeld PJ, Brown DM, Heier JS et al. MARINA Study Group. Ranibizumab for neovascular age-related macular degeneration. N Engl J Med 2006;355:1419-31.

[15] Brown DM, Kaiser PK, Michels M et al. ANCHOR Study Group. Ranibizumab versus verteporfin for neovascular age-related macular degeneration. $\mathrm{N}$ Engl J Med 2006;355:1432-44.

[16] Regillo CD, Brown DM, Abraham P et al. Randomized, double-masked, shamcontrolled trial of ranibizumab for neovascular age-related macular degeneration: PIER Study year 1. Am J Ophthalmol 2008;145(2): 239-48.

[17] Lalwani GA, Rosenfeld PJ, Fung AE et al. A variable-dosing regimen with intravitreal ranibizumab for neovascular age-related macular degeneration: year 2 of the PrONTO study. Am J Ophthalmol 2009;148(1):43-58. 
[18] Boyer DS, Heier JS, Brown DM et al. A Phase IIIb study to evaluate the safety of ranibizumab in subjects with neovascular age-related macular degeneration. Ophthalmology 2009;116(9):1731-9.

[19] Meyer CH, Eter N, Holz FD. SUSTAIN Study Group. Ranibizumab in Patients With Subfoveal Choroidal Neovascularization Secondary to Age-Related Macular Degeneration. Interim Results From the Sustain Trial. Invest Ophthalmol Vis Sci 2008;49: E-Abstract 273.

[20] Brown DM, Wang OW, Scott LC. HORIZON extension trial of Ranibizumab for wet AMD: subanalysis of year 1 results. AAO/SOE Joint Annual Meeting 2008, Atlanta, Georgia, USA.

[21] Kabbinavare F, Hurwitz HI, Fehrenbacher L et al. Phase II, randomized trial comparing bevacizumab plus fluorouracil (FU)/leucovorin (LV) with FU/LV alone in patients with metastatic colorectal cancer. J Clin Oncol 2003; 21:60-5.

[22] Hurwitz H, Fehrenbacher L, Novotny $W$ et al. Bevacizumab plus irinotecan, fluorouracil, and leucovorin for metastatic colorectal cancer. $N$ Engl J Med 2004;350:2335-42.

[23] Michels S S, Rosenfeld PJ, Puliafito CA et al. Systemic bevacizumab (Avastin) therapy for neovascular age-related macular degeneration. Twelve-week results of an uncontrolled open-label clinical study. Ophthalmology 2005;112(6):1035-47.

[24] Rosenfeld PJ, Moshfeghi AA, Puliafito CA. Optical coherence tomography findings after an intravitreal injection of bevacizumab (avastin) for neovascular age-related macular degeneration. Ophthalmic Surg Lasers Imaging 2005;36(4):331-5.

[25] Shahar J, Avery RL, Heilwell G et al. Electrophysiologic and retinal penetration studies following intravitreal injection of bevacizumab (Avastin). Retina 2006;26(3):262-9.

[26] AveryRL, Pieramici DJ, Rabena MD et al. Intravitreal bevacizumab (Avastin) for neovascular age-related macular degeneration. Ophthalmology 2006;113:363-72.

[27] Spaide RF, Laud K, Fine HF et al. Intravitreal bevacizumab treatment of choroidal neovascularization secondary to age-related macular degeneration. Retina 2006;26:383-90.

[28] Aisenbrey S, Ziemssen F, Volker M et al. Intravitreal bevacizumab (Avastin) for occult choroidal neovascularisation in age-related macular degeneration. Graefes Arch Clin Exp Ophthalmol 2007;245(7):941-8.

[29] Lazic R, Gabric N. Intravitreally administered bevacizumab (Avastin) in minimally classic and occult choroidal neovascularization secondary to age-related macular degeneration. Graefes Arch Clin Exp Ophthalmol 2007;245(1):68-73.

[30] Arevalo JF, Sánchez JG, Wu L et al. Intravitreal Bevacizumab for Subfoveal Choroidal Neovascularization in Age-Related Macular Degeneration at Twenty-four Months: The Pan-American Collaborative Retina Study Group.Ophthalmology 2010; Članak u tisku.

[31] Gamulescu MA, Radeck V, Lustinger B, Fink B, Helbig H. Bevacizumab versus ranibizumab in the treatment of exudative age-related macular degeneration. Int Ophthalmol 2010;30(3):261-6.

[32] Landa G, Made W, Doshi BV at al. Comparative study of intravitreal bevacizumab (Avastin) versus ranibizumab (Lucentis) in the treatment of neovascular agerelated macular degeneration. Ophthalmologica 2009;223(6):370-5. 
[33] Fong DS, Custis P, Howes J, Hsu JW. Intravitreal Bevacizumab and Ranibizumab for Age-Related Macular Degeneration: A Multicenter, Retrospective Study. Ophthalmology 2010;117(2):298-302.

[34] Shaha AR, Del Priore LV. Duration of action of intravitreal ranibizumab and bevacizumab in exudative AMD eyes based on macular volume measurements. $\mathrm{Br}$ J Ophthalmol 2009;93(8):1027-32.

[35] CATT Research Group, Martin DF, Maguire MG, Ying GS, Grunwald JE, Fine SL, Jaffe GJ. Ranibizumab and bevacizumab for neovascular age-related macular degeneration.N Engl J Med. 2011; 364(20):1897-908.

[36] Holash J, Davis S, PapadopoulosN et al. VEGF-Trap: a VEGF blocker with potent antitumor effects. Proc Natl Acad Sci USA 2002;99(17):11393-8.

[37] Nguyen QD, Shah SM, Hafiz G et al. A phase I trial of an IV-administered vascular endothelial growth factor trap for treatment in patients with choroidal neovascularization due to age-related macular degeneration. Ophthalmology 2006;113(9):1522.

[38] Heiner JS. VEGF Trap Eye Phase III Trial Results. VIEW 1 results.Paper presented at:Angiogenesis, Exudation and Degeneration 2011; Miami, Florida.

[39] Schmidt-Erfurt U. VEGF Trap Eye Phase III Trial Results. VIEW 2 results.Paper presented at: Angiogenesis, Exudation and Degeneration 2011; Miami, Florida.

[40] Reich S, Fosnot J, Akiko K et al. Small interfering RNA (siRNA) targeting VEGF effectively inhibits ocular neovascularization in a mouse model. Molecular Vision 2003;9:210-6.

[41] Tolentino MJ, Brucker AJ, Fosnot J et al. Intravitreal injection of vascular endothelial growth factor small interfering RNA inhibits growth and leakage in a nonhuman primate, laser-induced model of choroidal neovascularization. Retina 2004;24(4):660.

[42] Shen J, Samul R, Silva RL et al. Suppression of ocular neovascularization with siRNA targeting VEGF receptor 1. Gene Ther 2006;13(3):225-34.

[43] Mabjeesh NJ, Amir S. Hypoxia-inducible factor (HIF) in human tumorigenesis. Histol Histopathol 2007;22(5):559-72.

[44] Hunter T. Signaling: 2000 and beyond. Cell 2000;100:113-27.

[45] Robinsnon DR, Wu YM, Lin SF. The protein tyrosine kinase family of the human genome. Oncogene 2000;19:5548-57.

[46] Blume-Jensen P, Hunter T. Oncogenic kinase signalling. Nature 2001;411:355-65.

[47] Maier P, Unsoeld AS, Junker B at al. Intravitreal injection of specific receptor kinase inhibitor PTK787/ZK222584 improves ischemia-induced retinopathy in mice. Graefes Arch Clin Exp Ophthalmol 2005;243(6):593-600.

[48] Dawson DW, Volpret OV, Gillis P at al. Vascular permeability factor/vascular endothelial growth factor and the significance of microvascular hyperpermeability in angiogenesis. Curr Top Microbiol Immunol 1999;237:97-132.

[49] StellmachV, Crawford SE, Zhou W, Bouck N. Prevention of ischemia-induced retinopathy by the natural ocular antiangiogenic agent pigment epithelium-derived factor. Proc Natl Acad Sci USA 2001;98:2593-7.

[50] Mori K., Gehlbach P, Yamamoto S at al. AAV-mediated gene transfer of pigment epithelium-derived growth factor inhibits choroidal neovascularization. Invest Ophthalmol Vis Sci 2002;43:1994-2000. 
[51] Jaakkola A, Heikkonen J, Tommila $\mathrm{P}$ et al. Strontium plaque brachyterapy for exudative age related macular degeneration: 3 year results of a randomized study. Ophthalmology 112 (4), 2005;567-573.

[52] Finger PT, Berson A, Ng T, Szechter A. Ophthalmic plaque radiotherapy for agerelated macular degeneration associated with subretinal neovascularization. Am J Ophthalmol 1999; 127:170-177.

[53] Avila MP, Farah ME, Duprat JP et al. Twelve month short-term safety and visual acuity results from a multicentre prospective study of epiretinal strontium-90 brachytherapy with bevacizumab for the treatment of subfoveal choroidal neovascularization secondary to age-related macular degeneration. $\mathrm{Br} \mathrm{J}$ Ophthalmol. 2009; 93: 305-309.

[54] Kuppermann BD. Epimacular brachytherapy for the treatment of choroidal neovascularization associated with age related macular degeneration. Presented at the Retina sub-specialty meeting, AAO, 2008.

[55] Augustin AJ, Schmidt-Erfurth U. Verteporfin therapy combined with intravitreal triamcinolone in all types of choroidal neovascularization due to age-related macular degeneration.Ophthalmology 2006;113:14 -22.

[56] Spaide RF, Sorenson J, Maranan L. Photodynamic therapy with verteporfin combined with intravitreal injection of triamcinolone acetonide for choroidal neovascularization. Ophthalmology 2005;112(2):301-4.

[57] Chan WM, Lai TY, Wong AL, Tong JP, Liu DT, Lam DS.Combined photodynamic therapy and intravitreal triamcinolone injection for the treatment of subfoveal choroidal neovascularisation in age related macular degeneration: a comparative study. Br J Ophthalmol 2006;90(3):337-41.

[58] Schadlu R, Kymes SM, Apte RS. Combined photodynamic therapy and intravitreal triamcinolone for neovascular age-related macular degeneration: effect of initial visual acuity on treatment response..Graefes Arch Clin Exp Ophthalmol 2007;245(11):1667-72.

[59] Lazic R, Gabric N.Verteporfin therapy and intravitreal bevacizumab combined and alone in choroidal neovascularization due to age-related macular degeneration. Ophthalmology 2007;114(6):1179-85.

[60] Bakri SJ, Couch SM, McCannel CA, Edwards AO. Same-day triple therapy with photodynamic therapy, intravitreal dexamethasone, and bevacizumab in wet agerelated macular degeneration Retina 2009;29(5):573-8.

[61] Kaiser PK, Boyer DS, Garcia R et al. Verteporfin photodynamic therapy combined with intravitreal bevacizumab for neovascular age-related macular degeneration. Ophthalmology 2009;116(4):747-55.

[62] Shah GK, Sang DN, Hughes MS. Verteporfin combination regimens in the treatment of neovascular age-related macular degeneration. Retina 2009;29(2):133-48.

[63] Maier M, Haas K, Feucht N et al. Photodynamic therapy with verteporfin combined with intravitreal injection of bevacizumab for occult and classic CNV in AMD. Klin Monatsbl Augenheilkd 2008;225(7):653-9.

[64] Ahmadieh H, Taei R, Soheilian M, Riazi-Esfahani M, Ahadi H. Single-session photodynamic therapy combined with intravitreal bevacizumab for neovascular age-related macular degeneration. Eur J Ophthalmol 2008;18(2):297-300. 
[65] Ladewig MS, Karl SE, Hamelmann V et al. Combined intravitreal bevacizumab and photodynamic therapy for neovascular age-related macular degeneration. Graefes Arch Clin Exp Ophthalmol 2008;246(1):17-25.

[66] Oner A, Gumus K, Arda H, Yuce Y, Karakucuk S, Mirza E. Pattern electroretinographic results after photodynamic therapy alone and photodynamic therapy in combination with intravitreal bevacizumab for choroidal neovascularization in age-related macular degeneration. Doc Ophthalmol 2009;119(1):37-42.

[67] Rudnisky, C.J.Liu, C.,Ng, M. Weis, E. Tennant, M.T.S. Intravitreal bevacizumab alone versus combined verteporfin photodynamic therapy and intravitreal bevacizumab for choroidal neovascularization in age-related macular degeneration: Visual acuity after 1 year of follow-up. Retina 2010;30:548-54.

[68] Mataix J, Palacios E, Carmen DM, Garcia-Pous M, Navea A .Combined ranibizumab and photodynamic therapy to treat exudative age-related macular degeneration. An Option For Improving Treatment Efficiency. Retina 2010;Članak u tisku.

[69] Costagliola C, Romano MR, Rinaldi M et al. Low fluence rate photodynamic therapy combined with intravitreal bevacizumab for neovascular age-related macular degeneration.Br J Ophthalmol 2010;94(2):180-4.

[70] Debefve E, Pegaz B, Ballini JP, van den Bergh H.Combination therapy using verteporfin and ranibizumab; optimizing the timing in the CAM model. Photochem Photobiol 2009;85(6):1400-8. 


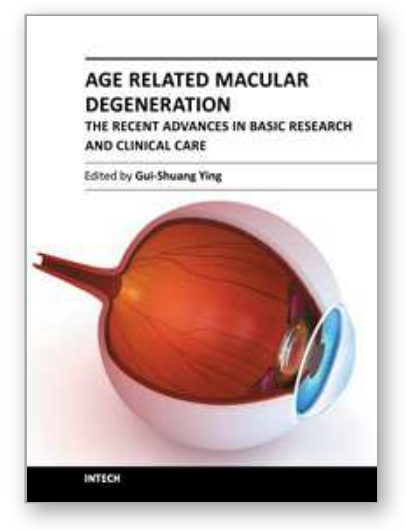

\author{
Age Related Macular Degeneration - The Recent Advances in Basic \\ Research and Clinical Care \\ Edited by Dr. Gui-Shuang Ying
}

ISBN 978-953-307-864-9

Hard cover, 300 pages

Publisher InTech

Published online 20, January, 2012

Published in print edition January, 2012

Age-related Macular Degeneration (AMD) is the leading cause of vision loss and blindness in the developed countries. In the past decade, great progress has been made in understanding the pathobiology and genetics of this blinding disease, as well as in finding new therapies for its treatment. These include the discovery of several genes that are associated with the risk of AMD, new anti-VEGF treatments for wet AMD and new imaging techniques to diagnose and monitor the AMD. All chapters in this book were contributed by outstanding research scientists and clinicians in the area of AMD. I hope this timely book will provide the basic scientists and clinicians with an opportunity to learn about the recent advances in the field of AMD.

\title{
How to reference
}

In order to correctly reference this scholarly work, feel free to copy and paste the following:

Ratimir Lazić and Nikica Gabric (2012). Treatment of Neovascular Age Related Macular Degeneration, Age Related Macular Degeneration - The Recent Advances in Basic Research and Clinical Care, Dr. Gui-Shuang Ying (Ed.), ISBN: 978-953-307-864-9, InTech, Available from: http://www.intechopen.com/books/age-relatedmacular-degeneration-the-recent-advances-in-basic-research-and-clinical-care/treatment-of-neovascular-agerelated-macular-degeneration

\section{INTECH}

open science | open minds

\author{
InTech Europe \\ University Campus STeP Ri \\ Slavka Krautzeka 83/A \\ 51000 Rijeka, Croatia \\ Phone: +385 (51) 770447 \\ Fax: +385 (51) 686166 \\ www.intechopen.com
}

\author{
InTech China \\ Unit 405, Office Block, Hotel Equatorial Shanghai \\ No.65, Yan An Road (West), Shanghai, 200040, China \\ 中国上海市延安西路65号上海国际贵都大饭店办公楼 405 单元 \\ Phone: +86-21-62489820 \\ Fax: $+86-21-62489821$
}


(C) 2012 The Author(s). Licensee IntechOpen. This is an open access article distributed under the terms of the Creative Commons Attribution 3.0 License, which permits unrestricted use, distribution, and reproduction in any medium, provided the original work is properly cited. 